\title{
Patterns of child mortality in rural area of Burkina Faso: evidence from the Nanoro health and demographic surveillance system (HDSS)
}

Navideh Noori ${ }^{{ }^{*}+}$, Karim Derra ${ }^{2 \dagger}$, Innocent Valea ${ }^{2,3}$, Assaf P. Oron ${ }^{1}$, Aminata Welgo ${ }^{2}$, Toussaint Rouamba ${ }^{2}$, Palwende Romuald Boua ${ }^{2}$, Athanase M. Somé2, Eli Rouamba², Edward Wenger ${ }^{1}$, Hermann Sorgho²,

Halidou Tinto ${ }^{2,3}$ and Andre Lin Ouédraogo ${ }^{1}$

\begin{abstract}
Background: Half of global child deaths occur in sub-Saharan Africa. Understanding child mortality patterns and risk factors will help inform interventions to reduce this heavy toll. The Nanoro Health and Demographic Surveillance System (HDSS), Burkina Faso was described previously, but patterns and potential drivers of heterogeneity in child mortality in the district had not been studied. Similar studies in other districts indicated proximity to health facilities as a risk factor, usually without distinction between facility types.

Methods: Using Nanoro HDSS data from 2009 to 2013, we estimated the association between under-5 mortality and proximity to inpatient and outpatient health facilities, seasonality of death, age group, and standard demographic risk factors.

Results: Living in homes 40-60 min and > 60 min travel time from an inpatient facility was associated with 1.52 (95\% Cl: 1.13-2.06) and 1.74 (95\% Cl: 1.27-2.40) greater hazard of under-5 mortality, respectively, than living in homes $<20$ min from an inpatient facility. No such association was found for outpatient facilities. The wet season (July-November) was associated with $1.28(95 \%$ Cl: 1.07, 1.53) higher under-5 mortality than the dry season (December-June), likely reflecting the malaria season.
\end{abstract}

Conclusions: Our results emphasize the importance of geographical proximity to health care, distinguish between inpatient and outpatient facilities, and also show a seasonal effect, probably driven by malaria.

Keywords: Children under 5, Child mortality, Burkina Faso, Spatial analysis, Demographic surveillance, HDSS, Nanoro

\footnotetext{
* Correspondence: nnoori@idmod.org

${ }^{\dagger}$ Navideh Noori and Karim Derra contributed equally to this work.

'Institute for Disease Modeling, Global Health Division, Bill \& Melinda Gates

Foundation, 500 5th Ave N, Seattle, WA 98109, USA

Full list of author information is available at the end of the article
}

\section{$\triangle B M C$}

(c) The Author(s). 2021 Open Access This article is licensed under a Creative Commons Attribution 4.0 International License, which permits use, sharing, adaptation, distribution and reproduction in any medium or format, as long as you give appropriate credit to the original author(s) and the source, provide a link to the Creative Commons licence, and indicate if changes were made. The images or other third party material in this article are included in the article's Creative Commons licence, unless indicated otherwise in a credit line to the material. If material is not included in the article's Creative Commons licence and your intended use is not permitted by statutory regulation or exceeds the permitted use, you will need to obtain permission directly from the copyright holder. To view a copy of this licence, visit http://creativecommons.org/licenses/by/4.0/ The Creative Commons Public Domain Dedication waiver (http://creativecommons.org/publicdomain/zero/1.0/) applies to the data made available in this article, unless otherwise stated in a credit line to the data. 


\section{Background}

Since the establishment of the Millennium Development Goals in 1990, there has been substantial progress in reducing child mortality globally, from 93 deaths in 1990 to 39 deaths in 2017 per 1000 live births. Nonetheless, an estimated 5.4 million children under age five died in 2017, out of which 2.5 million died during the first month of their life [1]. About half of child deaths occurred in sub-Saharan Africa [2]. In 2015, the Sustainable Development Goals (SDGs) were defined, aiming to reduce under-five mortality in every country to below 25 per 1000 live births by 2030 [3]. To achieve these targets, urgent action in sub-Saharan Africa is needed and higherquality information to guide this action [4]. Among sub-Saharan countries, Burkina Faso, where our study area is situated, has made great progress in reducing under- 5 mortality by about 58\% from 201 to 84.6 deaths per 1000 live births between 1990 and 2016, but this rate is still much higher than the SDGs [1].

To track progress towards child survival goals and to plan effective interventions for child health, identifying the major drivers of child mortality as well as datadriven estimates of child mortality are necessary [4]. However, countries with the highest child mortality burden lack civil registration and vital statistics (CRVS) systems accounting for all births, deaths and causes of death. In these countries, the location and timing of child deaths and the overall death rates, are highly uncertain. What we know about these crucial public-health questions is informed mostly by nationally representative surveys such as the Demographic and Health Surveys (DHS), conducted every several years.

A Health and Demographic Surveillance System (HDSS) is a local CRVS system that routinely monitors the health and demographic characteristics of a population living in a specific area. HDSS data facilitate detailed local studies of public health in general, and child mortality in particular. As of 2020, 49 HDSS sites participate in the International Network for the Demographic Evaluation of Populations and Their Health in Developing Countries (INDEPTH), recording the life events of over 3 million people in 17 African and Asian countries [5]. Several studies have investigated spatial [6-10], temporal $[11,12]$ and demographic $[11,13,14]$ factors affecting child mortality in HDSSs. However, no study to date has analyzed such patterns in the relatively new Nanoro HDSS in rural north-central Burkina Faso.

Risk of child mortality varies over space and time, and it is important to identify the areas at the highest risk in order to focus intervention-based efforts in those areas. One source of heterogeneity is proximity to health facilities $[15,16]$. Poor access to health care remains a concern in many low-income countries [17]. A growing number of studies have estimated the effect of distance from a health facility upon child mortality. The first meta-analysis of such studies was published in 2012 [16] and was updated more recently [18]. They found that living $>5 \mathrm{~km}$ away from a facility is associated with $62 \%$ higher neonatal mortality based on 4 studies, and $57 \%$ higher under-5 mortality based on 9 studies; both effects were deemed highly significant. In addition, a study aggregating 29 DHSs from 21 countries found that living $>10 \mathrm{~km}$ from a facility was strongly associated with $27 \%$ higher odds of neonatal mortality. Both the meta-analyses and the DHS-based study did not distinguish between smaller and larger facilities. Most above mentioned studies used simple Euclidean distance, or local expert opinion about distance or travel time, as the exposure variable. More sophisticated approaches to estimate real-life travel distance or time [19] have been published only rarely in this context.

Mortality also varies over time as a result of changes in health care-seeking, age and season of birth and death [11, 12], and environmental conditions [20]. In the Nouna HDSS, Burkina Faso, infants born during the rainy season were associated with higher mortality risk compared with those born during the dry season [11]. During the rainy season, flooded roads limit access to health care, especially in rural region. In most of West Africa, the rainy season also coincides with food shortage until the harvest arrives [11]. Seasonality also drives cause-specific mortality patterns due to malaria, pneumonia, and diarrhea, which were the leading causes of child mortality in Burkina Faso in 2010 [21]. Previous studies have also found associations between demographic factors such as birth spacing, twin births, ethnicity, maternal age, and child mortalities [11, 12]. Twin status in the Nouna HDSS, Burkina Faso was strongly associated with infant mortalities [11]. Children of young mothers also were at higher risk of mortality than older mothers [12].

Against this background, Nanoro presents some unique research opportunities. It is relatively new (our study begins with its inception in 2009), and thus less susceptible to potential participation (Hawthorne) effects seen in longer-standing HDSSs that had carried out many surveillance and research projects over the years. It is also unique in being completely rural yet hosting a strong tertiary health center in its main village. In addition, recent progress on global proximity estimates provides new tools for quantifying local patterns of access and inequality. Our study presents an attempt to leverage these opportunities, focusing on drivers of heterogeneity in child mortality risk within the Nanoro HDSS. 


\section{Methods}

\section{Study area and data}

Nanoro HDSS site was established in 2009 by the Clinical Research Unit of Nanoro (CRUN), located in the Centre Medicale Saint Camille de Nanoro (CMA), with the goal of evaluating population demography and health living conditions within the health district [22]. Nanoro is located about $85 \mathrm{~km}$ from the capital city, Ouagadougou. The Nanoro Demographic Surveillance Area (DSA) lies within the health district of Nanoro and includes 24 villages. All the households within the HDSS area participated in the survey. Initial census started from March to April 2009, and recorded housing, demographic, socio-cultural, and socio-economic characteristics of 54,781 individuals. Since then, census follow-up has been carried out every 4 months. Data collected at the individual level include births, deaths, pregnancies, in/out-migrations (temporary or permanent), and relationships (mother, father, and head of household). Data from 2009 to the end of 2013 were included in this analysis. Nanoro has two main seasons: a rainy season from June to October and a dry season from November to May [22]. In this study, to reflect the malaria mortality seasonality and the potential lag effect of rainy season, the wet season was defined as July to November and the other 7 months were defined as the dry season. There are 16 outpatient health facilities in the Nanoro health district and one inpatient health facility close to the village of Nanoro. There is also an inpatient health facility in Bousse just east of the district, which is the closest inpatient facility for some residents in the DSA, and therefore was included in this study (Fig. 1).

Proximity to both inpatient and outpatient health facilities was measured as Euclidean distance, travel time, and walking travel time. Travel time to the most accessible health facility was calculated using a global "friction surface" provided by the Malaria Atlas Project (MAP) at a resolution of $1 \mathrm{~km}$ for 2015, which estimates the travel time through every $1 \times 1 \mathrm{~km}$ grid square on Earth using the fastest feasible surface travel [19]. A companion algorithm calculates the fastest journey time between any two user-provided points. This index may better capture the opportunity cost of travel than Euclidean or network distance and reflects the information humans use to make transport decisions [19]. We also calculated walking travel time by modifying the friction surface developed by MAP, so that all roads received a fixed walking speed of $5 \mathrm{~km}$ per hour [19]. Fastest travel time was the main variable used to describe health-facility access in our models. Hereafter we will refer to this variable simply as "travel time." Models using the other proximity variables are shown in Supplementary Material.

\section{Statistical analysis}

We designed an observational study to identify the associations between various risk factors and child mortality. We estimated the survival probability of children under age five over the study's nearly 5-year period, as 1 minus the product of average age-specific monthly survival rates from birth through 60 months, multiplied by 1000 . Cox proportional hazards regression models [23] were used to estimate the association between under-5 survival and demographic, geographic, and seasonal risk factors. These include physical proximity to health facilities, seasonality of death events during the survey, age groups, gender, maternal education status, ethnicity, multiple birth status and religion. The relationship between each of these factors and mortality risk was assessed one at a time as both categorical and continuous variables (when possible). The final multivariable model adjusted for risk factors that were significant on a univariate model and available for the entire dataset. Among demographic factors, mother education status as well as multiple birth status were missing for children born before the start of HDSS data collection, and were therefore not included in the main model, but the estimates of their effect where not missing is shown in the supplementary material Table S1.

For each child, the follow-up time was taken as the time an individual was present within the age group during follow-up, which is the time from the date of first event in the survey, birth or enrollment or in-migration until age 5, out-migration, end of 2013, or death. Village was added as a cluster term to the model to estimate a robust variance. All the analyses and the mapping were performed in $\mathrm{R}$ using the survival and ggplot2 packages, respectively [24].

\section{Results}

\section{Demographics and child mortality}

The key demographic characteristics of the study population are given in Table 1. At any given time during the study period, about 8000 children under 5 years old lived in the district. Cumulatively 23,851 children were under age of 5 and in the district for at least part of the study period, contributing about 37,276 child-years of follow-up. Most children lived within 40 min of travel to an inpatient facility. Median household size was smaller among those living near an inpatient facility than those living further away. Nearly $25 \%$ of mothers living within $20 \mathrm{~min}$ of an inpatient facility had some level of formal education, in contrast with $12 \%$ or less of mothers living further away. For about $82 \%$ of children, their mothers were of Mossi ethnicity, with an even higher proportion among households > $40 \mathrm{~min}$ from an inpatient facility (Table 1). 


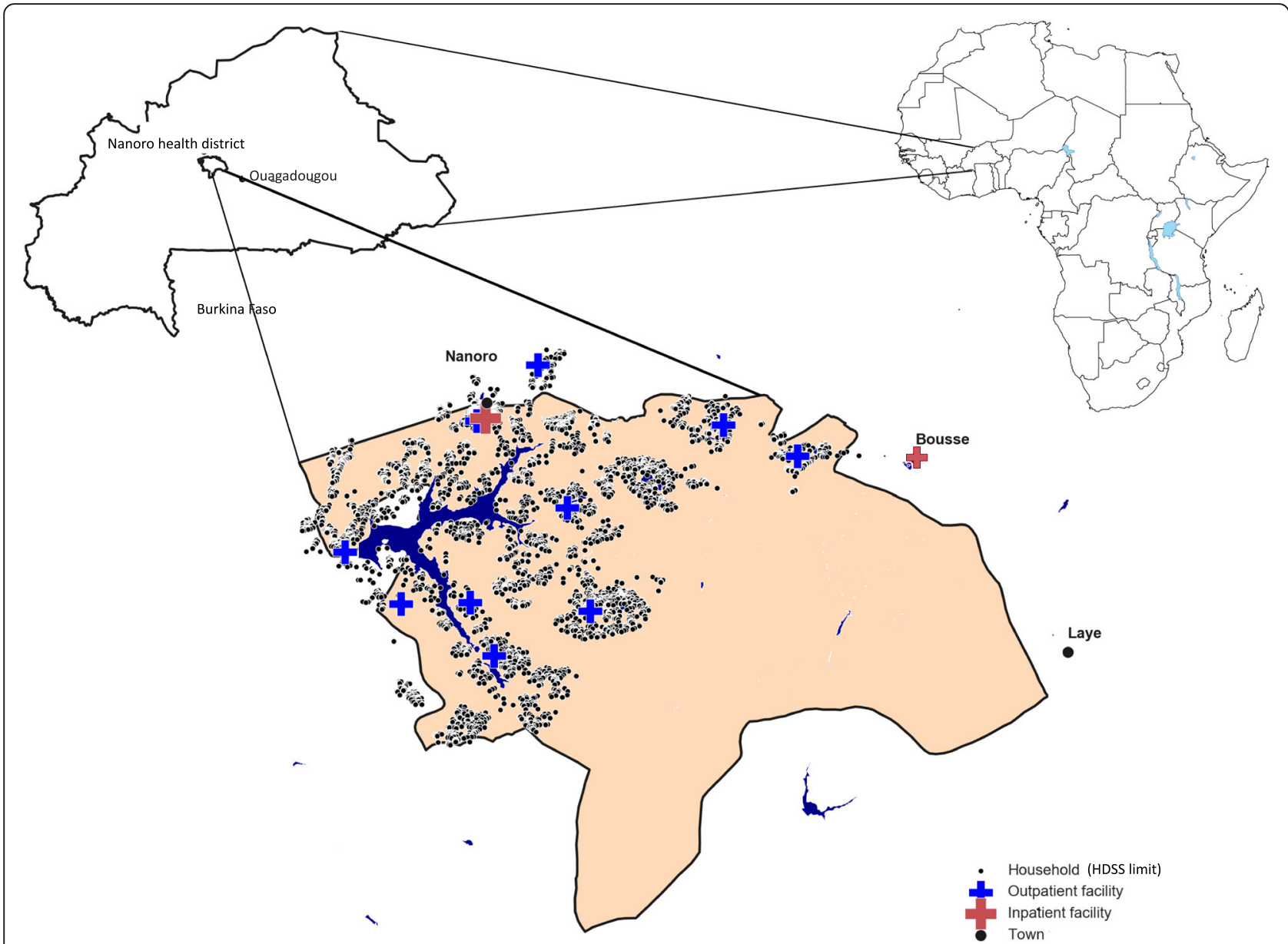

Fig. 1 Nanoro health district is located in the rural center of Burkina Faso. Green dots represent the HDSS households and red crosses represent the health facilities. The maps of Burkina Faso and the Nanoro health district are our own output using python programming software and publicly available administrative layers to visualize local geographical information system (GIS) data. The source of Africa map on the top right corner of figure is: https://whatsanswer.com/world-map/blank-map-of-africa-large-outline-map-of-africa/

The reported overall mortality rate among children under 5 in Nanoro HDSS during the study period was 64.9 deaths per 1000 live births (615 deaths). Within the district, the village of Nanoro had the lowest under-5 mortality at 29.4 per 1000 live births, approaching the 2030 SDG of $<25$. The southern and eastern edges of the DSA had a substantially higher mortality rate (91.8 per 1000 live births) (Supplementary Material, Figs. S1, S2 and S3).

\section{Factors associated with child mortality}

The association between child mortality and the variables described in Methods is summarized in Table 2. As expected, risk of death decreased with increasing age. Children between 1 to 2 years old were at lower risk of mortality by $48 \%(\mathrm{HR}=0.52,95 \% \mathrm{CI}=0.41-0.65)$ than infants, and the risk of mortality was lowest for children 3 to 4 years old ( $\mathrm{HR}=0.39$ vs. infants, $95 \% \mathrm{CI}=0.27$ 0.57) (Table 2).

\section{Seasonality}

The under-5 mortality hazard was higher during the wet season (Jul-Nov) ( $\mathrm{HR}=1.28,95 \% \mathrm{CI}=1.07-1.53)$ than the dry season (Table 2). Out-migration also had a clear seasonal pattern, and was higher during the dry season (supplementary material, Fig. S9).

\section{Proximity to health facilities}

Under-5 mortality increased significantly with increasing travel time to an inpatient health facility $(P<0.001)$. In particular, children living $40-60 \mathrm{~min}$ away from an inpatient facility experienced a 1.52 times higher mortality hazard $(95 \% \mathrm{CI}=1.13-2.06)$ than those living within $20 \mathrm{~min}$, and children living > $60 \mathrm{~min}$ away experienced a relative hazard of 1.74 (95\% CI $=1.27-2.40)$ (Table 2). The majority of individuals living within $0-20 \mathrm{~min}$ travel time from an inpatient health facility (translated to $0-5 \mathrm{~km}$ distance, approximately), are on the north side of the lake, and 
Table 1 Demographic characteristics of Nanoro HDSS for children under-5, 2009-2013

\begin{tabular}{|c|c|c|c|c|}
\hline & \multicolumn{4}{|c|}{ Travel time to inpatient health facilities } \\
\hline & {$[0-20) \min$} & {$[20-40) \min$} & {$[40-60) \min$} & $60+\min$ \\
\hline Number of deaths & 142 & 255 & 124 & 94 \\
\hline Number of children & 7039 & 10,266 & 3950 & 2596 \\
\hline Household size & $6(3,11)^{a}$ & $7(4,14)^{a}$ & $7(4,13)^{a}$ & $9(4,14)^{a}$ \\
\hline Number of outpatient health facilities & 3 & 3 & 6 & 4 \\
\hline Ratio of female to male children & 0.96 & 0.99 & 1.04 & 1.01 \\
\hline Mother's age at birth in year & $27.1(22.3,33)^{a}$ & $27.2(22.4,32.7)^{a}$ & $27.2(22.4,32.7)^{a}$ & $27.2(22.4,32.5)^{a}$ \\
\hline \multicolumn{5}{|l|}{ Maternal education status (\%) ${ }^{b}$} \\
\hline Some primary & 8 & 4 & 3 & 4 \\
\hline Some secondary & 8 & 2 & 2 & 2 \\
\hline Some tertiary & 0.3 & - & 0.1 & 0.1 \\
\hline No formal education & 75 & 88 & 90 & 89 \\
\hline Don't know / Underage & 8 & 6 & 5 & 4 \\
\hline \multicolumn{5}{|l|}{ Religion $(\%)^{c}$} \\
\hline Muslim & 33 & 28 & 43 & 40 \\
\hline Catholic & 39 & 31 & 33 & 39 \\
\hline Protestan & 8 & 5 & 4 & 4 \\
\hline Animist & 16 & 32 & 16 & 14 \\
\hline Unknown & 4 & 4 & 3 & 4 \\
\hline \multicolumn{5}{|l|}{ Polygamy/Monogamy (\%) } \\
\hline Monogamy & 14 & 11 & 12 & 11 \\
\hline Polygamy & 19 & 23 & 23 & 26 \\
\hline Unknown & 67 & 66 & 64 & 63 \\
\hline \multicolumn{5}{|l|}{ Ethnicity $(\%)^{c}$} \\
\hline Mossi & 82 & 78 & 90 & 87 \\
\hline Peulh & 1 & 2 & 2 & 3 \\
\hline Gourounsi & 9 & 12 & 1 & 2 \\
\hline Unknown & 8 & 8 & 7 & 8 \\
\hline \multicolumn{5}{|l|}{ Multiple birth status (\%) } \\
\hline Singleton & 95 & 97 & 95 & 96 \\
\hline Twin/Triplet/Quadruplet & 5 & 3 & 5 & 4 \\
\hline
\end{tabular}

${ }^{\mathrm{a}}$ Median and interquartile range

${ }^{b}$ Children born after the establishment of HDSS

${ }^{c}$ Characteristics of mothers of children under-5

have good access to the inpatient health facility at all seasons (supplementary material, Fig. S4). Similar associations were found when using Euclidean distance or walking travel time (supplementary material, Fig. S5 and Tables S1 and S2). By contrast, there was no statistically significant association between proximity to outpatient health facilities and under-5 mortality (supplementary material, Fig. S6, and Tables S1 and S2). Among other risk factors, females had lower mortality hazard than males, but the difference was not significant $(\mathrm{HR}=0.94,95 \% \mathrm{CI}=0.80-1.10)$ (Table
S1). Among the subgroup of children born after HDSS establishment, those in families with unknown religion or unknown ethnicity were associated with a higher risk of mortality (Table S1). In addition, risk of death was lower among children whose mothers received at least some formal education $(H R=0.48$, 95\% CI $=0.27-0.84)$. Lastly, as expected, children born after the HDSS establishment in multiple births faced substantially higher mortality hazard than those born in singleton births $(\mathrm{HR}=2.59,95 \% \mathrm{CI}=1.72-3.91)$ (Table S1). 
Table 2 Results of adjusted and unadjusted Cox regression models for under-5 mortality. Hazard Ratios are presented with 95\% confidence intervals in parentheses. The adjusted model was controlled for age group, travel time to inpatient health facilities and seasonality

\begin{tabular}{|c|c|c|c|c|c|}
\hline Parameters & Mortality per 1000 live births & Unadjusted Hazard ratio & $P$-value & Adjusted Hazard ratio & $P$-value \\
\hline \multicolumn{6}{|l|}{ Age group (month) } \\
\hline$\left[00^{12}\right]$ & $327^{\mathrm{a}}$ & - & - & - & - \\
\hline$(12-24]$ & 136 & $0.50(0.40,0.63)$ & $<0.001$ & $0.52(0.41,0.65)$ & $<0.001$ \\
\hline$(24-36]$ & 71 & $0.28(0.20,0.39)$ & $<0.001$ & $0.29(0.21,0.41)$ & $<0.001$ \\
\hline$(36-48]$ & 56 & $0.39(0.27,0.56)$ & $<0.001$ & $0.39(0.27,0.57)$ & $<0.001$ \\
\hline$(48-60]$ & 25 & $0.72(0.48,1.06)$ & 0.097 & $0.75(0.49,1.13)$ & 0.17 \\
\hline \multicolumn{6}{|c|}{ Travel time to inpatient health facilities (min) } \\
\hline$\left[\begin{array}{ll}0 & 20\end{array}\right)$ & 50.03 & - & - & - & - \\
\hline$\left[\begin{array}{ll}20 & 40\end{array}\right)$ & 63.44 & $1.23(0.89,1.68)$ & 0.21 & $1.24(0.89,1.71)$ & 0.20 \\
\hline$\left[\begin{array}{ll}40 & 60\end{array}\right)$ & 79.49 & $1.51(1.13,2.03)$ & 0.006 & $1.52(1.13,2.06)$ & 0.005 \\
\hline $60+$ & 88.51 & $1.74(1.28,2.38)$ & $<0.001$ & $1.74(1.27,2.40)$ & $<0.001$ \\
\hline \multicolumn{6}{|l|}{ Seasonality } \\
\hline Dry Season (Dec-June) & 64.49 & - & - & - & - \\
\hline Wet Season (July-Nov) & 65.22 & $1.44(1.15,1.81)$ & 0.0018 & $1.28(1.07,1.53)$ & 0.0074 \\
\hline \multicolumn{6}{|c|}{ Travel time to outpatient health facilities (min) } \\
\hline$[0-5)$ & 58.11 & - & - & - & - \\
\hline$[5-10)$ & 66.99 & $1.15(0.8,1.65)$ & 0.44 & & \\
\hline$[10-15)$ & 69.72 & $1.20(0.87,1.67)$ & 0.26 & & \\
\hline$[15-20)$ & 65.87 & $1.09(0.75,1.59)$ & 0.64 & & \\
\hline $20+$ & 63.41 & $0.99(0.58,1.69)$ & 0.99 & & \\
\hline
\end{tabular}

*Number of deaths within each age group

\section{Discussion}

Our study provides insight into child mortality patterns in the Nanoro health district, Burkina Faso by linking it to various demographic, spatial and temporal risk factors. One distinction of our study is the evaluation of proximity to both inpatient and outpatient health facilities. In the recent meta-analysis by Rojas-Gualdrand and Caicedo-Velazquez [18], the majority of studies included in its under- 5 mortality endpoint estimate measured distance from any health center with no distinction between inpatient and outpatient. There were also inconsistencies regarding the effect of proximity to health care on child and neonatal mortalities. In Malawi, DHS data showed no association between distance to delivery care and early neonatal mortality, and in Zambia, early neonatal survival was higher with increasing distance [25]. On the other hand, analysis of DHS data in Madagascar showed a higher risk of infant mortality among those who lived further from a health facility [26]. In rural western Burkina Faso, rural Ethiopia and Tanzania, proximity to health facilities was found to be a major risk factor for infant, child and overall under- 5 mortality $[15,16,27]$. Our analysis is in agreement with the latter studies, and indicates that impeded access to an inpatient health facility might be a major risk factor for child mortality. Our study also suggests that proximity to outpatient health facilities does not drive the pattern of child mortality in the study area. We speculate that outpatient health facilities do not provide the level of care children need in a life or death situation. We note the confounding factor that inpatient health facilities are usually located in towns and major villages, with better food, water, and other living conditions for residents, as well as generally higher education and socioeconomic status. Another distinction of our study is the use of the recently developed global proximity map that accounts for the spatial locations and properties of roads, railroads, rivers, water bodies, topographical characteristics, land cover, and national borders [19]. Accounting for these features leads to a more accurate measurement of proximity than Euclidean or network distance that has been commonly used in previous studies.

There was a significant association between seasonality of death and under-5 mortality, with the wet season having a higher mortality rate, reflecting the malaria mortality pattern. The higher rate of out-migration during the 
dry season also highlights its potential effect on the child mortality pattern.

Some of the limitations of our work are other risk factors that we have not accounted for and may be important to our outcomes, such as family wealth status, family health-seeking behavior, sanitation and hygiene information, and effects of flooding. Wealth status of households could highlight the distribution of resources and health services in the district. Furthermore, in families with access to improved sanitation facilities, children are less exposed to infectious diseases. Variations in healthseeking frequency between households can also affect child mortality risk. Flooding could also inundate road and therefore limit access to care. Adjusting for each of these factors may help better explain the heterogeneities in the data, and alter the relationship between the proximity to the health facilities and child mortality. Also, the travel time index we used in this study is based on the assumption that everyone might use the fastest travel method possible. However, our analysis using walking travel time showed a similar association with under- 5 mortality. An additional limitation is that the friction surface developed by MAP does not account for seasonal variations, which can affect travel time to health facilities. Last but not least, this is an observational study, and therefore any association is subject to potential confounding factors, as discussed above for inpatient facilities.

\section{Conclusions}

Our study highlights the importance of proximity to health care in rural Burkina Faso, and overall patterns of child mortality in the relatively new Nanoro HDSS site that was not studied before. It also emphasizes that inequity in mortality rate is not only seen between rural and urban areas, but also within a relatively small rural area. Our findings can help health policy makers and program developers in the health district and similar districts, to understand the potential effect of health infrastructure designs and the most effective locations of health facilities. Novel strategies, such as improved transportation to inpatient facilities during a child health emergency, strengthening outpatient health facilities, and training community health workers in the rural area, are necessary for mitigating the physical limitations to accessing health care in the area. Also, reducing the socioeconomic inequalities between rural and urban areas as well as within each area can help enhance access to health services for poor people and reduce child mortality $[20,28]$. Our work also highlights the role of demographic factors, and in particular maternal education. Expansion of educational attainment and development of women empowerment programs to increase women's health awareness, and improvement of maternal and postnatal care, can also help districts like Nanoro HDSS attain the SDGs.

\section{Abbreviations}

SDG: Sustainable Development Goals; HDSS: Health and Demographic Surveillance System; CRVS: Civil Registration and Vital Statistics;

DHS: Demographic and Health Surveys; INDEPTH: International Network for the Demographic Evaluation of Populations and Their Health in Developing Countries; CRUN: Clinical Research Unit of Nanoro; CMA: Centre Medicale avec Antenne Chirurgicale Saint Camille de Nanoro; DSA: Demographic Surveillance Area; MAP: Malaria Atlas Project

\section{Supplementary Information}

The online version contains supplementary material available at https://doi. org/10.1186/s12889-021-11483-4.

\begin{abstract}
Additional file 1: Figure S1. The Nanoro health district is divided to four regions; north, east, south and west of lake. Figure S2. Hazard ratios associated with the probability of mortality of children under-5. Risk factors reducing the probability of death have hazard ratios lower than 1 to the left of the vertical dashed line. Hazard ratios (yellow points), 95\% confidence intervals (horizontal lines) and the $p$ values are given. The variables with the yellow points on the vertical dashed line represent the reference groups. Figure S3. Mortality per 1000 live births per village for children under-5. Each circle represents a village and the size of circle represents the number of live births. The lighter color indicates lower mortality rate and darker color indicates a higher mortality rate. Figure S4. Travel time of children under-5, living in the Nanoro health district, from an inpatient health facility. Each circle represents an individual. Figure S5. Mortality per 1,000 live births for children under-5 versus subgroups of distance, travel time and walking travel time to inpatient health facilities. Circle size represents the number of births within each subgroup. Figure S6. Mortality per 1,000 live births for children under5 versus subgroups of distance, travel time and walking travel time to outpatient health facilities.Circle size represents the number of births within each subgroup. Figure S7. Mortality per 1000 live births for each event month. Figure S8. Mortality count by age group. Figure S9. Inand out-migration count by month. Table S1. Results of unadjusted Cox regression models for under 5 mortality. Hazard Ratios are presented with 95\% confidence intervals in parentheses. Table S2. Results of unadjusted cox regression models for under-5 mortality per 1000 live births. Each risk factor was fitted to the model as a continuous variable. Hazard Ratios are presented with 95\% confidence intervals in parentheses.
\end{abstract}

\section{Acknowledgements}

The authors wish to thank the individuals of the Nanoro HDSS for their participation and their cooperation in this project, and the Ministry of Health of Burkina Faso for providing support.

\section{Authors' contributions}

$\mathrm{NN}, \mathrm{KD}, \mathrm{IV}, \mathrm{APO}, \mathrm{ALO}$ participated in the design of the analysis. NN and KD conducted the analysis, and NN drafted the original manuscript. All authors revised the manuscript. KD, IV, AW, TR, PRB, AMS, ER, HS, HT designed the household survey and collected and cleaned the survey data. IV, APO, ALO supervised the project. HT, EW acquired funding and administered the project. ALO managed the project. The authors read and approved the final manuscript.

\section{Funding}

This publication is a collaborative research between the Clinical Research Unit of Nanoro in Burkina Faso and the Institute for Disease Modeling prior to its affiliation with the Bill \& Melinda Gates Foundation. The findings and conclusions contained within are those of the authors and do not necessarily reflect the official positions or policies of the Bill \& Melinda Gates Foundation. For NN, AO, EAW and ALO, this work was supported by Bill and Melinda Gates through the Global Good Fund. KD, IV, AW, TR, PRB, AMS, ER, HS, HT were supported by the Institute of Tropical Medicine, Antwerp through the Belgian Cooperation Framework Agreement with the Government of Burkina Faso. 


\section{Availability of data and materials}

The datasets used and/or analyzed during the current study are available from the authors upon reasonable request. HDSS INDEPTH Core Dataset 2009-2015 (Released 2019), is provided by the INDEPTH Network Data Repository: https://www.indepth-ishare.org/index.php/catalog/172/. Public access to the database is open and available on https://www.indepth-ishare. org/index.php/auth/login/?destination=catalog/172/get_microdata.

\section{Declarations}

\section{Ethics approval and consent to participate}

The ethical approval was waived by the Burkina Faso Ministry of Health, regarding the general population data of the HDSS (demographics and mortality data) used in this study.

\section{Consent for publication}

Not applicable.

\section{Competing interests}

The authors declare that they have no competing interests.

\section{Author details}

'Institute for Disease Modeling, Global Health Division, Bill \& Melinda Gates Foundation, 500 5th Ave N, Seattle, WA 98109, USA. ${ }^{2}$ Institut de Recherche en Sciences de la Santé (IRSS)/Clinical Research Unit of Nanoro (CRUN), Nanoro, Burkina Faso. ${ }^{3}$ Laboratory of Parasitology and Entomology, Centre Muraz, Bobo-Dioulasso, Burkina Faso.

\section{Received: 11 July 2020 Accepted: 6 July 2021}

Published online: 19 July 2021

\section{References}

1. World Health Organization: WHO - Children improving survival and wellbeing .2020. https://www.who.int/news-room/fact-sheets/detail/childrenreducing-mortality. Accessed 28 Oct 2020.

2. UNICEF: Child Mortality - UNICEF Data. 2014. https://doi.org/10.1016/S2214-1 09X(14)70280-3. https://data.unicef.org/topic/child-sunvival/under-five-mortality/. Accessed 28 Oct 2020.

3. World Health Organization: Health in 2015: from MDGs, Millennium Development Goals to SDGs, Sustainable Development Goals. Technical reporr 2015.

4. You D, Hug L, Ejdemyr S, Idele P, Hogan D, Mathers C, et al. Global, regional, and national levels and trends in under-5 mortality between 1990 and 2015, with scenario-based projections to 2030: a systematic analysis by the un inter-Agency Group for Child Mortality Estimation. Lancet. 2015; 386(10010):2275-86. https://doi.org/10.1016/50140-6736(15)00120-8.

5. Demographic Evaluation of Populations and Their Health in Developing Countries (INDEPTH). http://www.indepth-network.org/about-us. Accessed 5 June 2020.

6. Sankoh OA, Y'e Y, Sauerborn R, Mu'Llera O, Becher H. Clustering of childhood mortality in rural Burkina Faso. Int J Epidemiol. 2001;30(3):485-92. https://doi.org/10.1093/ije/30.3.485.

7. Becher $\mathrm{H}$. Analyses of mortality clustering at member HDSSs within the INDEPTH Network- an important public health issue. Glob Health Action. 2010;5476:1-10.

8. Becher H, Muller O, Dambach P, Gabrysch S, Niamba L, Sankoh O, et al. Decreasing child mortality, spatial clustering and decreasing disparity in North-Western Burkina Faso. Tropical Med Int Health. 2016;21(4):546-55. https://doi.org/10.1111/tmi.12673.

9. Quattrochi J, Jasseh M, Mackenzie G, Castro MC. Spatial analysis of under-5 mortality and potential risk factors in the Basse health and demographic surveillance system, the Gambia. Tropical Med Int Health. 2015;20(7):941-51. https://doi.org/10.1111/tmi.12490.

10. Alabi O, Baloye D, Doctor HV, Oyedokun OA. Spatial analysis of under-five mortality clustering in northern Nigeria: findings from Nahuche health and demographic surveillance system, Zamfara state. Int J Trop Dis Health. 2016; 15(1):1-10. https://doi.org/10.9734/JTDH/2016/24709.

11. Becher H, Müller O, Jahn A, Gbangou A, Kynast-Wolf G, Kouyaté B. Risk factors of infant and child mortality in rural Burkina Faso. Bull World Health Organ. 2004;82(4):265-73.
12. Becher H, Kauerniann G, Khomski P. Kouyat'e B. using penalized splines to model age and season-of-birth-dependent effects of childhood mortality risk factors in rural Burkina Faso. Biom J. 2009;51(1):110-22. https://doi.org/1 0.1002/bimi.200810496.

13. Desta BN, Assefa N, Damte TD, Hordofa LO. Neonatal mortality and its risk factors in eastern Ethiopia: a prospective cohort Study in Kersa Health and Demographic Surveillance System (Kersa HDSS). Epidemiol Biostat Public Health. 2016;13(4): e11938-1-8 https://dx.doi.org/10.1186\%2Fs40748-016-0035-8.

14. Ingole V, Kovats S, Schumann B, Hajat S, Rocklov J, Juvekar S, et al. Socioenvironmental factors associated with heat and cold-related mortality in Vadu HDSS, western India : a population-based case-crossover study. Int J Biometeorol. 2017;61(10):1797-804. https://doi.org/10.1007/s00484-017-13 63-8.

15. Schoeps A, Gabrysch S, Niamba L, Sie A, Becher H. The effect of distance to health-care facilities on childhood mortality in rural Burkina Faso. Am J Epidemiol. 2011;173(5):492-8. https://doi.org/10.1093/aje/kwq386.

16. Okwaraji YB, Edmond KM. Proximity to health services and child survival in low- and middle-income countries: a systematic review and meta-analysis. BMJ Open. 2012;2(e001196):1-9. https://doi.org/10.1136/bmjopen-2012-0011 96.

17. Karra M, Fink G, Canning D. Facility distance and child mortality: a multicountry study of health facility access, service utilization, and child health outcomes. Int J Epidemiol. 2017;46(3):817-26. https://doi.org/10.1093/ije/ dyw062.

18. Rojas-Gualdrón D, Caicedo-Velázquez B. Distance from healthcare facilities and early life mortality: a systematic review and meta-analysis. Rev Fac Nac Salud Pública. 2017;35(3):420-31. https://doi.org/10.17533/udea.rfnsp.v3 5n3a12.

19. Weiss DJ, Nelson A, Gibson HS, Temperley W, Peedell S, Lieber A, et al. A global map of travel time to cities to assess inequalities in accessibility in 2015. Nature. 2018;553(7688):333-6. https://doi.org/10.1038/nature25181.

20. Gruebner O, Khan MMH, Burkart K, Lautenbach S, Lakes T, Kramer A, et al. Spatial variations and determinants of infant and under-five mortality in Bangladesh. Health Place. 2017;47:156-64. https://doi.org/10.1016/j.healthpla ce.2017.08.012.

21. Sarrassat S, Meda N, Badolo H, Ouedraogo M, Some H, Bambara R, et al. Effect of a mass radio campaign on family behaviours and child survival in Burkina Faso : a repeated cross-sectional, cluster randomized trial. Lancet Glob Health. 2018;6(3):E330-41. https://doi.org/10.1016/S2214-109X(18)3 0004-4.

22. Derra K, Rouamba E, Tahita MC, Ouedraogo S, Kazienga A, Sorgho H, et al. Profile: Nanoro health and demographic surveillance system. Int J Epidemiol. 2012;41(5):1293-301. https://doi.org/10.1093/ije/dys159.

23. Andreson PK, Gill RD. Cox's regression model for counting processes: a large sample study. Ann Stat. 1982;10(4):1100-20

24. R Core Team: A language and environment for statistical computing; 2013. R Foundation for statistical computing, Vienna https://wwwr-projectorg/ Accessed 2015 Sept 08.

25. Lohela TJ, Campbell OMR, Gabrysch S. Distance to care, facility delivery and early neonatal mortality in Malawi and Zambia. PLoS One. 2012;7(12). https://doi.org/10.1371/journal.pone.0052110.

26. Kashima S, Suzuki E, Okayasu T, Louis R, Eboshida A, Subramanian SV. Association between proximity to a health center and early childhood mortality in madagascar. PLoS One. 2012;7(6). https://doi.org/10.1371/journa I.pone.0038370.

27. Kadobera D, Sartorius B, Masanja H, Mathew A, Waiswa P. The effect of distance to formal health facility on childhood mortality in rural Tanzania, 2005-2007. Glob Health Action. 2012;5(1):1-9. https://doi.org/10.3402/gha. v5i0.19099.

28. Bado AR, Susuman AS. Determinants of under-5 mortality in Burkina Faso. J Public Health. 2018:41(3):550-60. https://doi.org/10.1093/pubmed/fdy168.

\section{Publisher's Note}

Springer Nature remains neutral with regard to jurisdictional claims in published maps and institutional affiliations. 